Junichi Toyota

\title{
On binary features in the evolution of human language*
}

\section{Introduction}

In this paper, the importance of linguistic features in binary opposition is discussed from an evolutionary perspective, based on a hypothesis put forward by Toyota (2009a), termed kaleidoscopic grammar. In this framework, the evolution of language may imply two different stages, an initial non-binary stage and a later post-binary stage. What is pivotal in this development is the emergence of a binary pair from a single grammatical category, and once the binary pair is achieved, various complex structures can emerge easily. In other words, the binary pair is indispensable for the emergence of complex linguistic structure. This type of evolution is, in fact, pervasive beyond linguistic changes, which suggests how powerful the binary pair can be. There are numerous cases that can be explained using the kaleidoscopic grammar framework, but we focus on one of the major steps in language evolution, i.e. the stage where the grammatical category "verb" emerged from the single category "noun."

This paper is organised as follows: first, general comments on binary features are presented, serving as a background for the rest of the paper. Then an earlier state of human languages is introduced, focusing on the lexical categories noun and verb, and their timing of appearance. Noun and verb form a binary opposition and function as a base for further development towards complex grammatical structures. The underlying theme for these

I am grateful to Melisa Mustafović for discussion of the main idea presented here. Any shortcomings are, needless to say, my own. The following abbreviations are used in this paper: $\mathrm{PRS}=$ present; $\mathrm{PST}=$ past; $\mathrm{SG}=$ singular. 
developments is grammaticalisation, as argued in Heine and Kuteva (2007) in relation to the evolution of language. It is assumed here that grammaticalisation is a powerful tool to explain historical change of language, whether it is an evolutionary change or a recent historical change. After these points, a parallel developmental pattern between evolution and historical development is shown in order to highlight the importance of binary features at different levels. Finally, the importance of the binary features can influence grammaticalisation in general from an evolutionary perspective, indicating that the emergence of verb forming the noun-verb binary pair is the pivotal point in the evolution of languages.

\section{Evolution in terms of binary features}

Evolution of any kind goes through different stages, but what seems to be common among them is an earlier stage containing features in binary opposition. Binary opposition here refers to any features requiring their counterpart, and they do not have to be in a symmetrical opposition. Simple examples for binary opposition are pairs such as black-white, high-low, north-south, etc., but more complex ones include cases such as arrangements of leaves on trees (opposite, alternate and spiral). Toyota (2009a: 15-30) presents a wide range of evidence suggesting the presence of binary pairs, ranging from biological features (such as body structure) to archaeological factors (such as composition of earlier cave painting or shapes and designs of earlier artefacts). In embryology, for instance, as argued in Dawkins (1997: 204), having a symmetric binary pair of body structures in animals at the stage of embryo is "evolution of evolutionability." What is important here is that these pairs are not only common in biological features, but also in cultural and cognitive ones. It seems highly plausible that our ancestors were fully aware of various binary pairs and they demonstrated these in earlier artefacts and perhaps even took advantage of them.

In terms of evolution, a general pattern is that various features are commonly binary at the start, but become more complex as they develop. For instance, modern artistic designs often involve complex patterns and compositions, but they all stem from earlier simpler drawing of lines such as a combination of parallel lines. There are some notable exceptions, such as earlier Celtic cultures, which had already possessed complex patterns from the earliest records we can find, but the majority of cases involve a gradual transition from binary to more complex systems. It has been claimed that binary features are cognitively much easier to process (cf. Jablan 1995), 
and this is perhaps why they were predominantly used earlier. However, as our civilisation and our cognitive capacity were evolving, binary features incorporated various other options and became ternary or quaternary features (Toyota 2009a). In the earlier structuralist approach, these binary features are considered to develop into pairs of further binary pairs (cf. Lévi-Strauss $1965,1966)$, but a newly developed form does not have to be binary. For instance, food is either raw/fresh or rotten. This binary pair can be turned into ternary once food starts to be processed, forming raw v. rotten v. processed. After this stage, there are different kinds of processing, such as boiling, roasting, frying, etc., making the distinction even more complex in a sort of hierarchical order, e.g. raw v. rotten v. processed [boiled v. roasted v. fried].

\section{An earlier stage of human languages}

This type of binary pairs is not restricted to physical features or cultural artefacts, but our languages also follow this general pattern, since language is a product of various kinds of development, including physical (such as lowering of larynx), cognitive (such as ability to discuss indirect experience) and socio-cultural ones (such as changes in social relationship) (cf. Walker \& Shipman 1996, Cheney \& Seyfarth 1990, Dunbar 1996, Donald 1991, 1993, Tomasello 1999). When it comes to the structure of language, modern human languages possess so-called predicate-argument structure. This means that human language has several templates or patterns of structure and every utterance has to belong to one of them. The pattern of predicate-argument structure varies according to each language, but there are some basic patterns in each one. This structure also makes human language different from primate communication with respect to productivity and efficiency (cf. Hurford 2003), i.e. syntactic recursiveness. In order to achieve this, a certain degree of complexity in grammar is required, and the minimum requirement is noun and verb. Once these lexical categories are available, some patterns of recursiveness can be achieved.

The emergence of such complexity is very hard to date, since no convincing evidence, either linguistic or non-linguistic, can be found. In the earliest recorded languages, such as Old Egyptian (3,000-2,000 BC), or the earliest reconstructed languages, such as Proto-Indo-European (ca. $4,000 \mathrm{BC}$ ), the grammar already had certain patterns involving nouns and verbs. So the period is much earlier than 4,000BC. However, the distinction between noun and verb may not always be so clear-cut. For instance, In Old

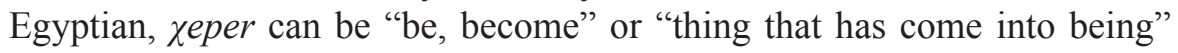


(Budge 1971: 141). Note that the category adjective is expressed as a part of the verbal paradigm, as shown in (1). Notice that $n f r$ "good" and wsh "large" carry inflectional markers for the tense. Compare it with a verbal clause in (2), where the tense is marked on the verb. This type of ambiguity is still common in some modern languages, and it has been even claimed that some languages lack verb or there is no categorical distinction between noun and verb (cf. Gil 2001, Lüpke 2005). Nevertheless, the human language about 4,000 to 5,000 years ago already had verbs, although some distinctions may be rather ambiguous from a perspective of modern languages.

Old Egyptian (Loprieno 1995: 112)

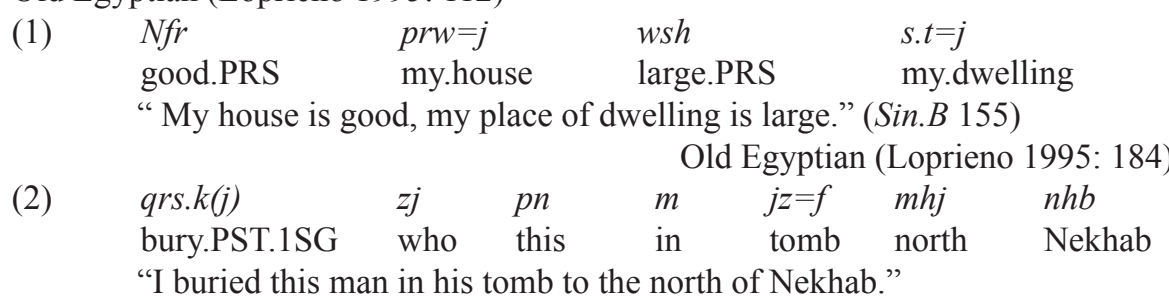

Old Egyptian (Urk. I 140,8)

Recursiveness of syntactic structure is a very powerful device to achieve the expressiveness of modern languages economically, but it is not entirely convincing that this feature appeared directly from a very primitive grammatical form, and it is more reasonable to assume the existence of some intermediate stages, each of which contributed to the next step. Hence, it is argued here that the awareness and the use of binary features in the earlier form of language were a crucial phase in language evolution. A problem here is how proto-languages reached a stage of binary opposition in grammar.

\subsection{Noun-verb opposition}

Although this is rather speculative, it has been assumed that at the earliest stage of language, the category noun dominated the grammar, perhaps along with a handful of verbs, such as motion verbs "come" and "go" (Aitchison 1996: 110-111; Heine \& Kuteva 2002: 390), although Hurford (1990, 2003) claims that it was pronouns, not nouns, that existed first. Heine and Kuteva (2007) more specifically analyse the emergence of noun and verb from an evolutionary perspective based on various grammaticalisation patterns. They trace back the original lexical categories using common grammaticalisation paths, and claim that various lexical (adjective, adverb, etc.) and grammatical (affixes, conjunctions, demonstrative, subordination markers, etc.) categories 
can be traced back to either noun or verb, but no further. Figure 1 illustrates such patterns, having different layers (from I to VI) as steps in development. Therefore, they claim that these two categories must be the most primitive ones in evolutionary terms. In addition, Heine and Kuteva (2007: 113) claim that in the process of grammaticalisation from the layer I to VI in Figure 1, meanings become more abstract, open-class items become closed-class, and meanings become less independent and referential. These features also suggest that the earlier tendencies better represent the characteristics of nouns, which put nouns in the layer I above the verb in the layer II. Note, however, that these are only common patterns and there are other possible developmental paths. For instance, adjectives can be derived from verbs, too, as demonstrated in the Old Egyptian example in (1).

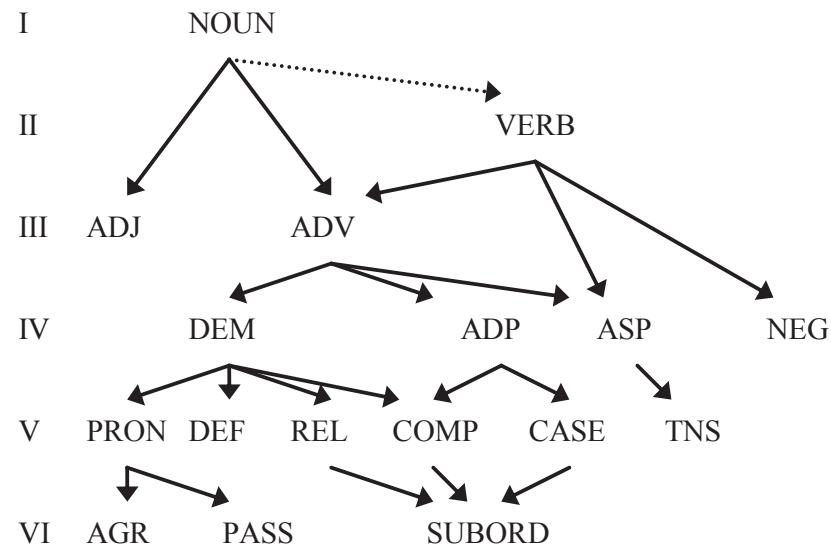

Notes: ADP = adpositions; ADJ = adjective; ADV = adverb; AGR = agreement; ASP $=$ aspect COMP $=$ complementizer; $\mathrm{DEF}=$ definite marker; $\mathrm{DEM}=$ demonstrative; $\mathrm{NEG}=$ negation $; \mathrm{PASS}=$ passive $; \mathrm{PRON}=$ pronoun $; \mathrm{REL}=$ relative clause marker; SUBORD $=$ subordination marker; $\mathrm{TNS}=$ tense.

Figure 1. Salient grammaticalisation paths of categorical shift (Heine and Kuteva 2007: 111)

Figure 1 suggests that the richness of grammatical structures in modern languages started after the layer II, which makes the noun-verb binary pair. It is assumed here, following Heine and Kuteva (2007), that nouns existed first and verbs emerged later. Thus, the emergence of the verb seems to be very important in the whole development of the human language. 


\subsection{The emergence of verbs}

As demonstrated in Figure 1, verbs can be evolutionarily derived from nouns. The developmental path from noun to verb has not been clearly identified, but Toyota (2009a) tentatively suggests that its internal mechanism seems to rely on different subtypes of nouns. With reconstruction of protolanguages, it seems plausible to argue that they often have so-called active alignment as a basic grammatical system (see also Lehmann 2002, Gamkrelidze \& Ivanov 1995, Szemerényi 1996, Mallory \& Adams 2006, Fortson 2010). What is unique is that the base of its structure is the nominal binary nature between active and inactive nouns. "The animate class can be viewed as an active class, i.e. one referring to objects capable of acting (or conceived of as capable of acting), while the inanimate class comprises nouns referring to objects incapable of acting" (Gamkrelidze \& Ivanov 1995: 238). This classification generally corresponds to the animate-inanimate distinction, but it is not wholly comparable. Exceptions are names of trees, river, fire, etc. which are considered to produce something. This made them active nouns or they had the active-inactive distinction. For example, "water" in Proto-Indo-European can be considered as animate *Hap ${ }^{h}$ " water, river, stream (as a moving element)" and inanimate * wot'ort "water (as a nonliving element)." As for the name of trees, the residues of such classification can be still found in later Indo-European languages (cf. Toyota \& Vlasa Florea 2009): the names of trees are often active, since they can bear fruits (a sign of productivity), while its fruits are inanimate, e.g. Latin pirus "pear tree;" mālus "apple tree" (animate), while pirum "pear"; mālum "apple" (as a fruit, inanimate) (Gamkrelidze \& Ivanov 1995: 238-239). This system is still used in some languages now, perhaps most notably in Algonquian languages, but also in other languages spoken in North America and the Caucasian region to varying degrees.

The semantic contents of active nouns can reflect on verbal meanings, in the sense of dynamism. This nominal system is highly likely to have existed before the emergence of verbs, and the distinction between active and inactive nouns in the nominal-only language indicates that the action was recognised, but there was simply no overt categorical distinction for verb. It can be claimed that this recognition of action is the beginning of the emergence of the verb. The animate nouns indicate the ability to initiate the action, which made a sharp contrast between naming items and describing actions. Thus, various semantic features in the active nouns created a ground for our cognition to develop and deal with abstract concepts, particularly those describing action. This is also reflected in the choice of the subject: it 
is argued that at the earlier stage, the clause only took an animate subject, acting either on another animate referent or an inanimate referent. So it can be claimed that the verb originated from the active noun, and the inactive noun was simply retained. Note that the active nouns stayed as nouns, too, but the action implied by them forced the verb to emerge. This relationship is schematised in Figure 2.

Active noun Inactive noun

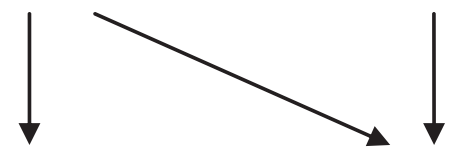

Verb Noun

Figure 2. Schematic representation of development of verb from active noun (Toyota 2009a: 56)

Note that as languages with active alignment developed, the inanimate subject appeared by the help of a suffix which turned inactive nouns into active ones (Gamkrelidze \& Ivanov 1995: 261-263). Such a pattern can be still found in some modern languages. For example, Fox, an Algonquian language spoken in eastern Iowa by about 500 people, does not allow a clause without an animate subject. When there is no animate subject, an activising suffix is added to turn the inanimate subject into the animate one. See Anderson (1997) for a detailed argument and examples.

Proto-languages with reconstruction as well as ancient languages with written records had a poor distinction of verb. At this stage, languages were made with a single lexical category, noun. It was not, however, until the emergence of the verb that languages became a powerful tool of communication. This suggests that the presence of the binary pair is a necessary element in human language in order for it to be fully functional.

\subsection{The Break-up of Binary Features}

Once we have a binary opposition of noun and verb, the base for complex grammar is made. Looking at much finer elements of grammar, some categories such as adjective are relatively poorly defined. This is so because the category adjective emerged as an intermediate category between noun and verb. Ternary or quaternary features of this sort are considered a natural result of historical development, since the complexity of grammar cannot be 
achieved without them. The breakout of various features of modern grammar created gradience, which resulted in possible intermediate categories like adjectives. Such grammatical features have been identified: Givón (1979: 235) claims that "in each instance, a crazy synchronic state of the grammar has arisen via diachronic changes that are highly natural and presumably motivated independently by various communicative factors" [emphasis original], or as Harris and Campbell (1995:261) put it, "[i]t is a commonplace of historical linguistics that changes leave residue." Despite the effort of these scholars, these grammatical features have been rather neglected in linguistic analysis, and have not received their deserved attention. The importance of gradient membership in linguistic analysis indicates that diachronic changes often break the earlier binary grammatical features and create the third or fourth degree features, as demonstrated in Section 4.

Language displays numerous binary features. To a greater extent at the lexical level, as Dawkins (1999: 15) says, "X is not a useful word unless there are some things that are not X." Such a binary nature was very obvious in ancient languages, and similar relationship can be still found in modern languages but to a slightly lesser degree. The difference, however, is that some of binary features in ancient languages, when evolved into their daughter languages, often turned into ternary or quaternary systems. This means that the binary pair may not play a central role any longer but exist peripherally. However, judging from the fact that almost every change has gone through the stage of binary opposition, this is a truly crucial stage in development.

\section{Parallel patterns in evolution and historical development}

The emergence of the verb is not a single case where languages are dependent on the presence of binary pairs. Below are some instances where similar parallel developmental paths can be found.

Evolutionarily speaking, no language had a tense system from the beginning. Instead, earlier languages had only aspect, a grammatical category that relates to the internal temporal structure of a situation. Each tense - past, present and future - can be dissected into finer components. For instance, a current event (i.e. present tense) can be considered ongoing, a state resulting from a past event, a habitual event, etc. These finer distinctions can fall under aspect. Tense was developed from aspect. Earlier, perfective and imperfective became past and non-past, respectively, as a base for tense (cf. Toyota 2008). This suggests that speakers at an initial stage were concerned with whether an action or a state has been (perfective) or is still ongoing (imperfective). 
This stems from the nominal distinction between active and inactive nouns. Active nouns can potentially continue acting or influencing other objects (i.e. still ongoing or imperfective), but inactive nouns do not have such a capacity and, therefore, the action has been completed (perfective). Since tense developed from aspect, the earlier tense was binary. This binary system in both aspect and tense became more complex, including progressive, habitual, etc. for aspect and future for tense. The distribution of tense and aspect can vary in each language, but the general developmental pattern suggests that the earlier stages, whether it is tense or aspect, were binary, and that ternary or further distinctions can only be found later.

Another obvious case is grammatical voice. Grammatical voice allows speakers to view the same event from different perspectives. It may contain different constructions, including active, passive, middle, inverse, applicative, causative, etc. and the distribution depends on each language. In spite of this diversity, the original voice distinction was the active voice alone, since the subject of a clause was by default realised by active nouns and no alternation was possible. When inactive nouns came to function as the subject, the predicate often denoted spontaneous events, since there was no argument with volitionality involved. The verbal markings for allowing the inactive noun to be the subject in a predicate later became the middle voice marker. At this stage, there appeared a binary pair of active and middle voice, and the emergence of other voice distinctions happened much later, perhaps within the past 2,000 to 3,000 years at most. The current diversity all stems from this binary pair, involving different degrees of volitionality and its coding.

Binary features in the above categories may be obvious once we consider them from an evolutionary perspective, but they can be also found in some unexpected linguistic structures, and the emergence of the words "yes" and "no" can be due to the pressure from the presence of a binary opposition. According to Toyota (2009b), the development started with the word for "no", stemming from a negative marker in each language. Then "no" stood on its own for a while, which forced speakers to come up with its affirmative counterpart. Generally speaking, the "yes" word comes from a copula, normally in an infinitive or third person singular present indicative form, e.g. Modern Greek has ne "yes" and ochi "no", and their origin can be found in Classical Greek: $n e$ is derived from the copula einai "be", and ochi from the negative marker oux (before aspirated words) /ouk (everywhere else). ${ }^{1}$ Some languages can present historical evidence for the developing stages of these words. The case of Proto-Uralic (ca. 4,000 BC) is an example:

1 I am grateful to Marilena Thanassoula for these Greek examples. 
Décsy (1977: 81-82) notes that there was no word for "yes", but the word for "no", i.e. e, existed. In modern Uralic languages, the yes-no opposition exists, and this can be a case of a requirement for opposite features in languages, i.e. the presence of "no" on its own is considered to have forced its opposition "yes" to appear.

These cases of post proto-language development suggest that the binary oppositions are also useful at a later development of languages. It is clear by now that a set of binary pairs in different parts of grammar often functions as an onset of various changes towards a complex structure, whether it is evolutionary or historical change. Thus, there is a parallel pattern of change in both evolutionary and historical development concerning the binary pair.

\section{Implications from binary features}

The instances presented so far suggest that binary oppositions are crucial onsets, and what arises from these onsets is normally governed by grammaticalisation. In this later development, there are several stages (including extension, desemanticisation, decategorisation and erosion) and these stages are unidirectionally observed. In order for a specific lexical item to go through all these stages, at least about 2,000 to 3,000 years are necessary. This timing is a case of grammaticalisaiton that takes place in isolation, but in recent works by Heine and Kuteva $(2005,2006)$ they proposed that the basic principle of grammaticalisation can be also observed in contact-induced changes in a much shorter period of time, and a number of historical changes are in fact somehow contact-induced.

The use of principles of grammaticalisation to the study of linguistic evolution often attracts questions concerning the timing. If each process of gramamticalisation requires around 3,000 years, then we simply need, based on the six stages in Figure 1, around 15,000 years at most to complete a change from a noun-only language to the complex grammars of modern languages. There are various pieces of archaeological and paleontological evidence suggesting an approximate date for the origin of language (such as the lowering of larynx, cf. Lieberman 1968; Noble and Davidson 1996; Carstairs-McCarthy 1999: 125-131), giving the date around 50,000 to 100,000 years ago, and there is a significant gap between this assumption and an estimate based on the reconstruction using grammaticalisation. Newmeyer (2002: 366) points this out: 
The entire progression from full lexical category to affix can take fewer than 2,000 years to run its course. As they [Heine and Kuteva 2002] note, if there were no process creating new lexical categories, we would be in the untenable position of saying that languages remained constant from the birth of Homo sapiens until a couple of millennia ago at which point the unidirectional grammaticalization processes began.

Newmeyer's account of the duration for one sequence of grammaticalisation may be more realistic than what has been stated in this paper, especially considering the contact-induced changes, but his perspective concerning the time span can be slightly broadened. It is clear that grammaticalisation has started much earlier than a couple of millennia ago (see Deutscher 2000 for evidence from Akkadian). However, an important point invoked by his question is that there must have been a point in the history of human language where grammaticalisation started and there had been a more stable grammatical structure earlier.

Concerning this point, Heine and Kuteva (2007: 49, fn. 35) claim that "future research might reveal that there is justification to divide the evolution of grammar into two salient phases, say, an earlier phase characterized by some specific state of grammaticali[s]ation and a later one showing a different state of grammaticali[s]ation," although they do not see a need for this distinction yet. Based on the binary features approach taken here, it is possible to argue that these two salient phases can be identified, a pre-binary phase and a postbinary phase concerning the noun-verb distinction, i.e. between layers II and III in Figure 1. Along this line of argument, grammaticalisation in the sense of following certain stages happened after layer II, yielding an estimate of 12,000 years. However, this does not show the age of our language. Instead, this is the time in which grammaticalisation in a conventional sense can explain changes. Prior to this, languages spent much time in creating a noun-verb binary opposition. Roughly speaking, about nine-tenths of the evolution (considering the age of language as 100,000 years) were spent on creating a binary feature.

Whether grammaticalisation can be found in the pre-binary phase is open to question, but binary features form an important phase in the development of languages. Binary features can be compared to the evolution of the nucleus in biological evolution: the break-through in the animal and plant evolution is the emergence of the eukaryotic cell (the cell with a nucleus) from the prokaryotic cell (the cell without a nucleus), as Wolpert (2003: 3) puts it, "once you had the eukaryotic cell from the point of view of evolution and 
development it was downhill all the way, very very easy." When we discuss human evolution, for instance, we take it for granted that there are eukaryotic cells available and it is easier to discuss gradual change from Homo erectus to Homo sapiens, for instance, but it is much harder to discuss earlier stages. It seems that a certain crucial point exists in evolution, and it took so long to achieve this stage in evolution; it looks as if the most intensive effort was paid to the creation of this point. Thus, from this perspective, the creation of the noun-verb pair can be given a new status in the evolution of human language.

\section{Summary}

This paper has argued that the binary pair is a powerful feature in both the evolution and the recent historical change of language. It is indeed true that our language requires nouns and verbs to form predicates and to fully meet our daily communicative needs. It is easier for us to consider from our modern perspective that almost all modern languages have more than noun and verb in their lexical categories. However, it has been argued in this paper that this current state of grammar is all due to the emergence of verb. Once there is a noun-verb opposition, it is easy to develop complex grammatical systems through grammaticalisation, as schematically represented in Figure 1. The importance of binary oppositions is not restricted to evolution, but recent historical changes also suggest the importance of binary pairs, possibly recapitulating earlier evolutionary changes of languages.

This line of argument would suggest that there can be two stages in linguistic evolution, i.e. the pre-binary stage and the post-binary stage. The pivotal change here is, needless to say, the emergence of verb. Grammaticalisation can easily explain how noun and verb can turn into more complex grammatical structures, i.e. the post-binary stage, but the applicability of grammaticalisation to the pre-binary stage is open to question for the moment. What is important is that our language has spent so much time to come up with the basic binary pair noun and verb, and once there is one, the rest of the development is very easy. This indicates how powerful binary pairs can be. 


\section{References}

Aitchison, J. (1996). The Seeds of Speech: Language Origin and Evolution. Cambridge: Cambridge University Press.

Anderson, G. D. S. (1997). On “animacy maximization” in Fox (Mesquakie). Journal of American Linguistics, 63, 227-247.

Budge, E. A. W. (1971). Egyptian Language. London: Routledge \& Kegan Paul.

Carstairs-McCarthy, A. (1999). The Origins of Complex Language: An Inquiry into the Evolutionary Beginnings of Sentence, Syllables, and Truth. Oxford: Oxford University Press.

Cheney, D. H. \& Seyfarth, R. M. (1990). How Monkeys See the World. Chicago: University of Chicago Press.

Dawkins, R. (1997). Climbing Mount Improbable. London: Penguin.

Dawkins, R. (1999). Unweaving the Rainbow. London: Penguin.

Décsy, G. (1977). The Uralic Protolanguage: A Comprehensive Reconstruction. Bloomington: Eurolingua.

Deutscher, G. (2000). Syntactic Change in Akkadian: The evolution of sentential complementation. Oxford: Oxford University Press.

Donald, M. (1991). Origins of the Modern Mind: Three Stages in the Evolution of Culture and Cognition. Cambridge (MA): Harvard University Press.

Donald, M. (1993). Précis of Origins of the Modern Mind: Three Stages in the Evolution of Culture and Cognition. Behavioral and Brain Sciences 16, 737-791.

Dunbar, R. (1996). Grooming, Gossip and the Evolution of Language. London: Faber and Faber.

Fortson, B. W. IV. (2010). Indo-European Language and Culture (2 ${ }^{\text {nd }}$ ed.). Chichester (West Sussex): Wiley-Blackwell.

Gamkrelidze, T. V. \& Ivanov, V. V. (1995). Indo-European and Indo-Europeans: A Recpnstruction and Historical Analysis of a Proto-Language and ProtoCulture (part 1): text. (English version by Johanna Nichols). Berlin: Mouton de Gruyter.

Gil, D. (2001). Creole, Complexity, and Riau Indonesian. Linguistic Typology 5, $325-371$.

Givón, T. (1979). On Understanding Grammar. New York: Academic Press.

Harris, A. C. \& Campbell, L. (1995). Historical Syntax in Cross-Linguistic Perspective. Cambridge: Cambridge University Press.

Heine, B. \& Kuteva, T. 2002. On the evolution of grammatical forms. In A. Wray (Ed.), The Transition to Language (pp. 367-397). Oxford: Oxford University Press.

Heine, B. \& Kuteva, T. (2005). Language Contact and Grammatical Change. Cambridge: Cambridge University Press. 
Heine, B. \& Kuteva, T. (2006). The Changing Languages of Europe. Oxford: Oxford University Press.

Heine, B. \& Kuteva, T. (2007). The Genesis of Grammar. Oxford: Oxford University Press.

Hurford, J. R. (1990). Beyond the roadblock in linguistic evolution studies. Behavioral and Brain Sciences 13, 736-37.

Hurford, J. R. (2003). The neural basis of predicate-argument structure. Behavioral and Brain Sciences 26, 261-316.

Jablan, S. V. (1995). Theory of symmetry and Ornament. Belgrade: Mathematical Institute.

Lehmann, W. P. (2002). Pre-Indo-European. Journal of Indo-European Studies Monograph 41.

Lévi-Strauss, C. (1965). Le triangle culinaire. L'Arc 26, 19-29.

Lévi-Strauss, C. (1966). The Savage Mind. London: Weidenfeld and Nicolson.

Lieberman, P. (1968). Primate vocalization and human linguistic ability. Journal of the Acoustical Society of America 44, 1574-1584.

Loprieno, A. (1995). Ancient Egyptian. Cambridge: Cambridge University Press.

Lüpke, F. (2005). A Grammar of Jalonke Argument Structure. Ph.D. Dissertation, Katholieke Universiteit Nijmegen, Nijmegen.

Mallory, J. P. \& Adams, D. Q. (2006). The Oxford Introduction to Proto-IndoEuropean and the Proto-Indo-European World. Oxford: Oxford University Press.

Newmeyer, F. (2002). Uniformitarian Assumptions and Language Evolution Research. In A.Wray (Ed.), The Transition to Language (pp. 359-375). Oxford: Oxford University Press.

Noble, W. \& Davidson, I. (1996). Human Evolution, Language and Mind: A Psychological and Archaeological Inquiry. Cambridge: Cambridge University Press.

Szemerényi, O. J. L. (1996). Introduction to Indo-European Linguistics. Oxford: Clarendon Press.

Tomasello, M. (1999). The Cultural Origin of Human Cognition. Cambridge (Mass.): Harvard University Press.

Toyota, J. (2008). Aspect as a sign of historical development. Studia Romanica Tartuensia 6, 133-151.

Toyota, J. (2009a). Kaleidoscopic Grammar: Investigation into the Nature of Binarism. Newcastle upon Tyne: Cambridge Scholars Publishing.

Toyota, J. (2009b). On the evolutionary history of 'yes' and 'no'. In Zlatev, J. et al. (Eds.), Studies in Language and Cognition (pp. 485-498). Newcastle upon Tyne: Cambridge Scholars Publishing.

Toyota, J. \& Vlasa Florea, F. (2009). Grammatical gender: a case of neuter in Old English and languages of Europe. Facta Universitatis: linguistics and literature 7, 163-172. 
Walker, A. \& Shipman, P. (1996). The Wisdom of Bones: in Search of Human Origins. London: Weidenfeld \& Nicholson.

Wolpert, L. (2003). Evolution of development. In K. Eichmann (Ed.), The Biology of Complex Organisms - Creation and Protection of Integrity (pp. 3-13). Basel: Birkhäauser Verlag. 